\title{
Recognition memory across the adult life span: The role of prior knowledge
}

\author{
LARS BÄCKMAN \\ Karolinska Institute, Stockholm, Sweden
}

\begin{abstract}
Two experiments were performed to investigate the effects of prior knowledge on recognition memory in young adults, younger old adults, 76-year-olds, and 85-year-olds. In Experiment 1, we examined episodic recognition of dated and contemporary famous persons presented as faces, names, and faces plus names. In Experiment 2, four types of faces were presented for later recognition: dated familiar, contemporary familiar, old unfamiliar, and young unfamiliar. The results of both experiments showed that young adults performed better with contemporary than with dated famous persons, whereas the reverse was true for all groups of older adults. In addition, the data of Experiment 2 indicated that (1) young adults showed better recognition for young than for old unfamiliar faces, (2) younger old adults performed better with old than with young unfamiliar faces, and (3) the two oldest age groups showed no effect of age of face. These results suggest that the ability to utilize rich semantic knowledge to improve episodic memory is preserved in very old age, although the aging process may be associated with deficits in the ability to utilize prior knowledge to support memory when the underlying representation lacks semantic and contextual features. The overall data pattern was discussed in relation to the notion that, with increasing adult age, there is an increase in the level of cognitive support required to enhance episodic remembering.
\end{abstract}

Recent reviews of the literature on memory and aging suggest that although older adults are typically impaired in performing tasks that draw on basic episodic memory skills, the magnitude of the age-related deficit in episodic remembering varies greatly as a function of multiple external and subject-related factors (Bäckman, 1989; Bäckman, Mäntylä, \& Herlitz, 1990; Hultsch \& Dixon, 1984, 1990). Regarding external factors, several investigators have made the observation that age-related differences in memory performance are pronounced in tasks that involve little cognitive support (e.g., free recall of single words), whereas tasks in which the instructions, the retrieval conditions, or the material itself support the learner in initiating appropriate memory operations show reduced or eliminated age differences (e.g., Bäckman, 1985a, 1986; Bäckman \& Nilsson, 1984, 1985; Craik, 1983, 1985; Craik, Byrd, \& Swanson, 1987; Hultsch \& Pentz, 1980). Although the results of a number of studies indicate that older adults require more cognitive support than young adults do to optimize episodic memory functioning, it should be noted that there are exceptions to this pattern.

\footnotetext{
This research was supported by grants from The Bank of Sweden Tercentenary Foundation (Nos. 85/69 and 88/327) and The Commission for Social Research, Swedish Ministry of Health and Social Affairs (Nos. $85 / 2023$ and 88/20). I am grateful to James Chumbley, Fergus Craik, and several anonymous reviewers for providing constructive comments on earlier versions of this paper. I would also like to thank Björn Josefsson for assistance in the experimental and statistical work. Requests for reprints should be sent to Lars Bäckman, Section of Psychology, Stockholm Gerontology Research Center, Dalagatan 9-11, S-113 82 Stockholm, Sweden.
}

There is research indicating a parallel improvement in young and old adults as a function of increasing cognitive support (e.g., Mitchell, Hunt, \& Schmitt, 1986; Rabinowitz \& Craik, 1986), and there are studies showing that young adults may be more effective than older adults in utilizing some forms of support (e.g., Kliegl, Smith, \& Baltes, 1989; Simon, 1979). Thus, the relationship between degree of cognitive support, age, and memory performance is complex, and whether young or older adults will selectively improve performance because of increasing support will depend on multiple interactions among tasks, materials, and subjects (Bäckman et al., 1990; Craik et al., 1987).

With respect to subject-related factors, it has been demonstrated that knowledge of subjects' verbal skills (e.g., Dixon, Hultsch, Simon, \& von Eye, 1984), taskrelevant prior knowledge (e.g., Barrett \& Wright, 1981), educational background (e.g., Craik et al., 1987), personality characteristics (Arbuckle, Gold, \& Andres, 1986), and specific memory-related skills (e.g., Yesavage, 1985) may be helpful in predicting the level of memory performance of older adults and the magnitude of agerelated differences in memory. It is important to note that there are multiple interactions between these subjectrelated factors and the aforementioned external factors. One empirical generalization is that when the memory capabilities of the old adult are low, due, say, to a low level of education or verbal skill (Craik et al., 1987), to very old age (Nilsson et al., 1987), or, in the extreme case, to dementia (Karlsson et al., 1989), there is an increase in the degree of cognitive support required to op- 
timize memory functioning. Knowledge of such interaction patterns would seem to be imperative for one to achieve the best understanding of adult memory development.

One subject-related variable that has received considerable attention among investigators during recent years is that of prior knowledge (see Dixon \& Bäckman, in press, for a review). There is evidence that the availability of task-relevant prior knowledge may increase the level of recall of older adults and sometimes result in the elimination of age differences in memory performance. In cognitive aging research, a common way of manipulating the variable of prior knowledge is to select to-be-remembered (TBR) information for which age groups (i.e., young adults vs. older adults) differ with respect to prior knowledge. Typically, this is accomplished by varying the datedness of the information (i.e., dated vs. contemporary), the underlying assumption being that because age and cohort groups may have experienced relatively unique cultural and historical events, there may be age-related differences in prior knowledge for some historically relevant topics. In agreement with these propositions, Hultsch and Dixon (1983) found that older subjects recalled more propositions from a text for which normative data indicated a high level of knowledge for older adults (a biographical sketch of Mary Pickford) compared to a text for which normative data indicated a low level of knowledge for older adults (a biographical sketch of Steve Martin). In addition, the results of that study showed exactly the opposite pattern of results for young subjects.

This interaction between adult age and datedness of information has been found with other types of materials, such as single words (Barrett \& Wright, 1981; Erber, Galt, \& Botwinick, 1985; Worden \& Sherman-Brown, 1983) and common names (Hanley-Dunn \& McIntosh, 1984). Thus, the importance of pertinent prior knowledge for the goodness of episodic remembering in old age is well documented. Note that, in contrast to what most often is the case in research on memory and aging, the facilitative effects on memory observed in these studies originated from internal (schematic) sources, rather than from external sources (e.g., instructions, cues, a rich input).

As with most research on memory and aging, however, these studies involved comparisons of groups of young adults (usually in their early 20s) with only one group of older adults (ranging between 60 and 75 years of age). Recent research from our own laboratory suggests that it may be incorrect to generalize data patterns from earlier to later portions of the late adult life span. Bäckman and Karlsson (1986) showed that whereas 73-year-olds were able to utilize cognitive support in the form of organizational instructions at encoding to improve recall (Hultsch, 1969,1971 ), 82-year-olds did not benefit from pretask suggestions to organize the information. Karlsson et al. (1989) demonstrated that although both 73- and 82-yearolds were able to utilize encoding support in the form of motor action during learning (e.g., Bäckman, 1985b; Dick, Kean, \& Sands, 1989), the beneficial effect was greater for 73- than for 82-year-olds. Similarly, Bäckman, Herlitz, and Karlsson (1987) showed that both 73- and 82-year-olds free-recalled more names of dated than of contemporary famous persons, the recall advantage being somewhat greater for the 73-year-olds. Thus, evidence suggests differences in the ability to utilize contextual and cognitive support for remembering among different cohorts of normal old adults.

The results of Bäckman et al. (1987) suggest that although there may be differences between 73- and 82-yearolds in their ability to utilize prior knowledge to improve episodic memory, this ability is relatively well preserved in very old age. However, several theoretically relevant issues pertaining to the relationship among prior knowledge, episodic memory, and aging remain unsolved. In the two experiments reported in this article, an attempt was made to examine this relationship in closer detail. In both experiments, groups of young adults, younger old adults (in their 60s), 76-year-olds, and 85-year-olds participated. The experimental task selected was that of recognition memory for faces and names. There are several reasons why recognition memory, in general, and face recognition memory, in particular, constitute an interesting task in this context. In a review of effects of prior knowledge on memory, Alba and Hasher (1983) noted that whereas recall varies greatly with the amount of taskrelevant prior knowledge, recognition varies minimally. On the basis of these and related findings, Alba and Hasher suggested that prior knowledge influences memory at retrieval rather than at encoding and storage. However, in a recent paper, Bäckman and Herlitz (1990) have reported that older adults in their mid 60 s showed better episodic recognition for dated than for contemporary famous faces. If operating exclusively at retrieval, one should not expect effects of prior knowledge in tasks providing a substantial amount of retrieval support, such as face recognition. Thus, the results of Bäckman and Herlitz suggest that prior knowledge may influence memory also at encoding. However, the data pattern obtained by Bäckman and Herlitz needs to be replicated. In addition, it remains unknown whether or not old individuals in their 70 s and 80 s possess the ability to utilize prior knowledge to improve recognition memory.

Concerning face recognition memory, in general, there is evidence for an age-related deficit in discriminating old from new faces (see, e.g., Bartlett \& Leslie, 1986; Ferris, Crook, Clark, McCarthy, \& Rae, 1980; A. D. Smith \& Winograd, 1978). In a recent paper, Bartlett, Leslie, Tubbs, and Fulton (1989) provided evidence suggesting that this deficit may be due to a reduced proficiency in performing a "careful matching" of test items against face representations in memory, and in distinctiveness of stimulus encoding. However, although there is evidence that aging is associated with deficits in face recognition 
memory, it is unknown whether there are differences in patterns of face recognition performance among different cohorts of healthy older adults.

\section{EXPERIMENT 1}

In Experiment 1, people famous today and people who attained their fame during the 1930s and 1940s were presented in three different presentation formats: face, name, and face plus name, for purposes of later recognition. The manipulation of presentation format was done in order to explore the relationship between recoding and utilization of prior knowledge in episodic recognition. There is evidence that older adults are at a disadvantage in situations in which optimal memory performance rests on a transformation of the initially encoded event from a visual input format to an auditory memory code (Arenberg, 1968; McGhie, Chapman, \& Lawson, 1965; Taub, 1972), or from an auditory input to a visual memory code (Bäckman, 1986; Winograd \& Simon, 1980). In a similar vein, it has been proposed that a deficit in elaboration of the information to be remembered constitutes an important source of the episodic memory impairment that accompanies the normal aging process (see, e.g., Craik \& Rabinowitz, 1984; Craik \& Simon, 1980).

To the extent that efficient utilization of prior knowledge rests not only on the availability of appropriate knowledge structures, but also on the activation of these structures, it follows that the likelihood of observing effects of prior knowledge on memory in old age may increase as a function of increasing richness of the materials. In other words, when the original event is rich in itself and does not require any further mental transformations, such as the face plus name condition in this experiment, older adults may be especially likely to exhibit beneficial effects of prior knowledge on memory.

\section{Method}

Subjects. A total of 60 subjects divided into four equally large age groups (15 each) participated in the experiment: young adults (10 fernales, 5 males; $M$ age $=22.3$ years, range $=18-26$ years ), younger old adults ( 9 females, 6 males; $M$ age $=66.2$ years, age range $=62-69$ years), 76-year-olds (11 females, 4 males), and 85year-olds (11 females, 4 males). The young subjects were high school or college students. The younger old subjects were recruited from a local senior citizens club. The samples of 76- and 85-yearolds were participants in a large scale medical investigation at the University Hospital in Umes involving all 76- and 85-year-olds living in Umed. All subjects lived in the community, reported being in good health, and had sufficient visual and auditory capabilities to manage the sensory demands of the experiment.

An attempt was made to match the age groups as well as possible on educational background. The young subjects had completed an average of 12.73 years of formal education $(S D=1.68$, range $=10-15$ years); the younger old subjects averaged 13.00 years of schooling ( $S D=1.66$, range $=9-16$ years $)$; the 76-year-old subjects had a mean educational background of 12.27 years (SD $=2.22$, range $=8-15$ years); and the 85-year-old subjects averaged 10.00 years of schooling $(S D=1.66$, range $=7-13$ years $)$. An analysis of variance (ANOVA) on the education data revealed a significant main effect of age $\left[F(3,56)=9.03, M S_{e}=3.11\right.$, $p<.0001]$. A Newman-Keuls analysis $(p<.05)$ indicated that this effect was due to the fact that the 85-year-old subjects had completed fewer years of education than the other three age groups.

All subjects were given a 35-item multiple-choice synonym test. The mean scores were $30.23(S D=2.98$, range $=25-34), 31.12$ $(S D=2.93$, range $=28-35), 29.86(S D=3.41$, range $=24-34)$, and $29.14(S D=5.03$, range $=23-35)$ for young, younger old, 76-year-old, and 85-year-old subjects, respectively. An ANOVA on these data showed no reliable age effect $(p>.10)$. Thus, although there was an age-related effect for education, there were no age-related differences in verbal ability, as indexed by the present vocabulary test.

Materials and Procedure. The TBR materials comprised a total of 120 famous Swedish persons. Sixty of these persons attained their fame between 1930 and 1950 , and the remaining 60 attained their fame during the 1980s. The subjects' prior knowledge of the experimental materials was determined on the basis of normative data from previous research (Bäckman \& Herlitz, 1990; Bäckman \& Karlsson, 1985), in which it was demonstrated that young adults had more knowledge of people famous today than of people famous during the $1930 \mathrm{~s}$ and $1940 \mathrm{~s}$, whereas the reverse was true for different groups of older adults (see also Hultsch \& Dixon, 1983; Perlmutter, Metzger, Miller, \& Nezworski, 1980). Note that the results from some of these normative studies (Bäckman \& Karlsson, 1985; Perlmutter et al., 1980) indicated that older adults have more knowledge of dated famous persons than of contemporary famous persons and that the opposite applies to young adults, whereas the results from other studies (Bäckman \& Herlitz, 1990; Hultsch \& Dixon, 1983) suggest that the representations may also be richer and more elaborate for cohort-relevant famous persons. In the present experiment, both the dated and the contemporary materials comprised 12 individuals from each of five domains: politics, literature, music, movies, and sports.

All of the 120 TBR items were prepared as faces, names, and faces plus names. The TBR items were counterbalanced so that 5 subjects per age group received Item 1 as face, Item 2 as name, and Item 3 as face plus name, 5 subjects received Item 1 as name, Item 2 as face plus name, and Item 3 as face, and 5 subjects received Item 1 as face plus name, Item 2 as face, and Item 3 as name, and so forth. Items were presented by means of an automatic slide projector, the slides being $5.1 \times 5.1 \mathrm{~cm}$. For the face and face plus name conditions, black and white photographs were used. No photographs with unusual facial expressions, jewelry, clothing, or hair styles were included. The mean ages of the TBR faces when the pictures were taken were 44.1 years and 36.4 years for dated and contemporary faces, respectively. For the name condition, first names and surnames printed in large type (Times, 25 point) were used to optimize legibility. For the face plus name condition, the names were attached at the lower part of the pictures. Items were projected onto a screen $120 \times 120 \mathrm{~cm}$ in size. Viewing distance was adjusted individually in order to obtain an optimal visual acuity.

The subjects were individually tested. A total of 60 items were presented at study. Rate of presentation was $5 \mathrm{sec}$ per item and the interitem interval was $2 \mathrm{sec}$. Following presentation of the last item, there was a 20 -min interval before the recognition test was given. During this interval, the synonym test was administered and background data were collected. The recognition test was self-paced. The subjects made their yes/no judgments orally, and the responses were recorded by the experimenter. The 60 target items (10 per datedness $\times$ presentation format category) were here presented in the same format as during study, together with 60 distractors from the same six categories (10 each). Three subjects per subgroup received Items 1-60 as targets and Items $61-120$ as distractors, and 2 subjects per subgroup received Items 61-120 as targets and Items $1-60$ as distractors. Within these constraints, each subject 
received a unique presentation order at both study and test. The experiment took approximately $1 \mathrm{~h}$ to complete, and each subject received the equivalent of $\$ 10$ (U.S.) for their participation.

\section{Results and Discussion}

Subjects' hits and false alarms were transformed into $d^{\prime}$ scores. To evaluate the data statistically, we conducted a 4 (age: young adults, younger old adults, 76-year-olds, 85 -year-olds) $\times 2$ (item type: dated, contemporary) $\times$ 3 (presentation format: face, name, face plus name) ANOVA based on $d^{\prime}$ scores, with repeated measures on the last two factors. The ANOVA revealed significant main effects of age $\left[F(3,56)=18.84, M S_{\mathrm{e}}=3.02\right.$, $p<.0001]$, item type $\left[F(1,56)=5.06, M S_{\mathrm{e}}=.86\right.$, $p<.05]$, and presentation format $[F(2,112)=10.08$, $\left.M S_{\mathrm{e}}=.70, p<.0001\right]$. The effect of item type was due to the fact that dated items $(M=2.48)$ were recognized better than contemporary items were $(M=2.26)$. Newman-Keuls analyses indicated that the young subjects $(M=2.85)$ and the younger old subjects $(M=3.08)$ had higher overall $d^{\prime}$ scores that did the 76-year-old subjects $(M=2.26)$, who in turn performed better than the 85year-old subjects did $(M=1.30)$. It is noteworthy that there were no overall performance differences between young and younger old adults; the age-related performance deficit observed was seen in the two oldest age groups. The Newman-Keuls analyses also revealed that faces plus names $(M=2.60)$ were recognized better than faces $(M=2.38)$, which were recognized better than names $(M=2.12)$.

Furthermore, the interaction between age and item type was reliable $\left[F(3,56)=8.79, M S_{\mathrm{e}}=.86, p<.0001\right]$. This interaction is shown in Table 1 , where it can be seen that the young subjects performed better with contemporary than with dated items, whereas all three groups of older subjects performed better with dated than with contemporary items. Newman-Keuls analyses indicated that all differences between item types within age groups were statistically significant. This pattern of results extends past research (Bäckman \& Herlitz, 1990) indicating that prior knowledge enhances recognition memory in young adults as well as in different cohorts of healthy older adults. In addition, the data on presentation format indicate that recognition memory performance increases as a function of increasing richness of the materials. Finally, the lack of significant interactions between age and

Table 1

Mean Proportion Hits (H) and False Alarms (FA), and Mean $d^{\prime}$ Score Across Age and Item Type

\begin{tabular}{lccccccc}
\hline & \multicolumn{3}{c}{ Contemporary } & & \multicolumn{3}{c}{ Dated } \\
\cline { 2 - 4 } \cline { 5 - 7 } Age Group & $\mathrm{H}$ & FA & $d^{\prime}$ & & H & FA & $d^{\prime}$ \\
\hline Young & .90 & .03 & 3.17 & & .81 & .05 & 2.52 \\
Younger old & .88 & .05 & 2.83 & & .90 & .02 & 3.33 \\
76-year-olds & .76 & .10 & 1.97 & & .84 & .06 & 2.54 \\
85-year-olds & .59 & .20 & 1.07 & .64 & .12 & 1.53 \\
\hline
\end{tabular}

presentation format and among age, item type, and presentation format $(F \mathrm{~s}<1)$ suggests that older adults do not benefit selectively from a rich presentation format in this task situation.

\section{EXPERIMENT 2}

In Experiment 1, the variable of prior knowledge was manipulated through the use of items that varied in datedness, the assumption being that the older age groups would possess more knowledge of dated famous persons, whereas the opposite would be true for young adults. In the literature on face recognition, there is evidence that a somewhat different type of prior knowledge may affect performance. For example, it has been demonstrated that white subjects recognize unfamiliar white faces better than unfamiliar black faces, whereas the reverse is true for black subjects (see, e.g., Brigham \& Barkowitz, 1978; Chance, Goldstein, \& McBride, 1975; Feinman \& Entwistle, 1976; Galper, 1973). Note, however, that the interaction pattern in these and in related studies may be asymmetrical. Malpass and Kravitz (1969) found the same-race effect to be true for white, but not black subjects, whereas Brigham and Williamson (1979) found superior recognition for same-race faces for black, but not for white subjects. Likewise, Bartlett and Leslie (1986) reported that although young subjects recognized unfamiliar young faces better than unfamiliar old faces, old subjects failed to show an effect of age of face. However, as pointed out by the authors, the asymmetry obtained may have been due to the fact that the degree of match between subject age and face age was greater for the young than for the older subjects.

Same-race or same-age effects are typically attributed to a general stimulus familiarity factor; because individuals are more often exposed to other individuals of the same race or the same age than to individuals of other races or ages, they are also more proficient in discriminating among same-race or same-age faces (see, e.g., Shepherd, 1981; Shepherd, Deregowski, \& Ellis, 1974). It is commonly held that a facilitation of recognition of unfamiliar same-age or same-race faces is due to more elaborated prototypes for different parts of the face, a more selective perception, and a more distinctive encoding of critical facial features (Shepherd, 1981).

Although researchers (e.g., Bartlett \& Leslie, 1986; Elliott, Wills, \& Goldstein, 1973) seem to agree that effects of type of face on recognition memory for unfamiliar faces are due to differences in the representation of faces, there is an important difference between schemata in the form of prototypical knowledge for different types of unfamiliar faces and schemata in the case of familiar faces. Whereas the latter type of schemata may involve various types of verbal features (e.g., semantic, contextual) in addition to physical features, only physical features of faces are likely to be available in the former type of schemata (Bruce, 
1979; Ellis, 1981). Thus, the underlying knowledge representation that may support memory is richer and more elaborate for familiar than for unfamiliar faces.

In Experiment 2, four different types of faces were presented for a later recognition test: dated/familiar, contemporary/familiar, old/unfamiliar, and young/unfamiliar. It was assumed that the dated/familiar and old/unfamiliar faces would be cohort-relevant for the three groups of older adults, whereas the contemporary/familiar and young/unfamiliar faces would be cohort-relevant for the young adults. The experiment had two main purposes. First, an attempt was made to replicate the results of Experiment 1 . Second, by manipulating prior knowledge both in terms of datedness (dated vs. contemporary) and age of face (old vs. young), we sought to explore the relative utility of these forms of prior knowledge for face recognition memory in adulthood and old age.

\section{Method \\ Subjects. New samples of 14 young subjects ( 8 females, 6 males; $M$ age $=23.8$, range $=19-27$ years $), 14$ younger old adults $(9$ females, 5 males; $M$ age $=68.5$, range $=63-70$ years $), 1476$ - year-olds ( 10 females, 4 males), and 14 85-year-olds (11 females, 3 males) participated in the experiment. Recruitment and selection procedures for the four groups of subjects were identical to those of Experiment 1. \\ The young subjects had completed an average of 13.86 years of formal education $(S D=1.10$, range $=12-16$ years $)$; the younger old subjects averaged 13.36 years of schooling $(S D=1.78$, range $=9-16$ years); the 76-year-old subjects had a mean educational background of 12.53 years $(S D=2.03$, range $=9-15$ years $)$; and the 85 -year-olds averaged 9.86 years of schooling $(S D=1.66$, range $=7-13$ years). An ANOVA revealed a significant main effect of age for educational background $\left[F(3,52)=15.79, M S_{\mathrm{e}}=2.81\right.$, $p<.0001$ ]. As was true in Experiment 1, Newman-Keuls anal- yses indicated that the 85-year-old subjects had completed fewer years of education than the other three age groups had. \\ The subjects completed a 35-item multiple-choice synonym test. The mean scores were $28.35(S D=3.71$, range $=21-33), 31.50$ $(S D=2.59$, range $=27-35), 29.71(S D=3.51$, range $=23-34)$, and $27.67(S D=2.76$, range $=22-32)$ for the young, younger old, 76-year-old, and 85-year-old subjects, respectively. An ANOVA conducted on the vocabulary data yielded a main effect of age $\left[F(3,52)=4.09, M S_{e}=10.13, p<.05\right]$. Newman-Keuls analyses showed that this effect was due to the fact that the youn- ger old subjects had higher vocabulary scores than did the young and 85-year-old subjects.}

Materials and Procedure. The materials comprised 120 black and white photographs. Sixty of these portrayed famous Swedish individuals, 30 of whom were famous during the 1930s and 1940s and 30 of whom are famous today. These pictures were selected from the pool of pictures used in Experiment 1, and both the dated and the contemporary pictures comprised six persons from the domains of politics, literature, music, movies, and sports, respectively. The remaining 60 photographs portrayed faces of unfamiliar persons, 30 of whom were young and 30 of whom were old. The mean ages of the TBR faces at the time the pictures were taken were 32.6 years, 39.2 years, 29.5 years, and 76.2 years for contemporary/ familiar, dated familiar, young/unfamiliar, and old/unfamiliar faces, respectively. No faces with unusual facial expressions, jewelry, clothing, or hair styles were used.

The subjects were individually tested. At study, 15 faces from each of the four categories of faces were presented for purposes of later recognition. The faces were presented in the same way as in Experiment 1 with respect to apparatus, presentation format, and presentation rate. Following presentation of the last face, there was a 20-min retention interval during which the subjects completed the vocabulary test and a questionnaire concerning background information. In the self-paced recognition test, the 60 target faces were presented along with 60 distractors ( 15 from each of the four categories of faces), and the subjects were asked to do a yes/no recognition judgment for each presented face. As in Experiment I, the responses were given orally and recorded by the experimenter. Half the subjects in each age group received Faces $1-15$ in each category as targets and Faces $16-30$ as distractors, whereas the reverse was true for the other half in each age group. All subjects were presented with the faces in a unique order at both study and test. The experiment took about $1 \mathrm{~h}$ to complete, and each subject received the equivalent of $\$ 10$ (U,S.) for participating

\section{Results and Discussion}

Hits and false alarms in the recognition test were transformed into $d^{\prime}$ scores. The recognition data were analyzed with a 4 (age: young adults, younger old adults, 76-yearolds, 85-year-olds) $\times 2$ (cohort relevance: young, old) $\times 2$ (familiarity: familiar, unfamiliar) ANOVA, with repeated measures on the last two factors. The ANOVA revealed significant main effects of age $[F(3,52)=26.21$, $\left.M S_{\mathrm{e}}=1.20, p<.0001\right]$ and familiarity $[F(1,52)=$ $\left.119.63, M S_{\mathrm{e}}=.63, p<.0001\right]$. Familiar faces $(M=$ 2.68) were generally recognized better than unfamiliar faces $(M=1.52)$, and Newman-Keuls analyses revealed that the best overall performance was shown by young subjects $(M=2.92)$ followed by younger old subjects $(M$ $=2.43)$, 76-year-old subjects $(M=1.87)$, and 85-yearold subjects $(M=1.18)$, in descending order. In addition, the interactions of group and cohort relevance $\left[F(3,52)=31.78, M S_{\mathrm{e}}=.31, p<.0001\right]$ and of group and familiarity $\left[F(3,52)=3.12, M S_{\mathrm{e}}=.63, p<.05\right]$ were reliable. However, these interactions have to be qualified in relation to the significant triple interaction among age, cohort relevance, and familiarity $[F(3,52)=$ $5.87, M S_{e}=.38, p<.011$. This interaction is shown in Table 2.

Newman-Keuls analyses revealed that for both familiar and unfamiliar faces, young adults and younger old adults performed better with cohort-relevant faces than with the corresponding cohort-irrelevant faces. The two oldest age groups, however, failed to show an effect of age of face for unfamiliar faces, although they performed better with dated/familiar than with contemporary/familiar faces. This pattern of data replicates the results of Experiment 1, indicating that preexperimental semantic knowledge enhances face recognition memory across the adult life span. In addition, the data of Experiment 2 suggest that there may be an age-related deficit in the ability to utilize prior knowledge in the form of a general stimulus familiarity, assumed to result in a more distinctive encoding of facial features for unfamiliar faces (see, e.g., Ellis, 1981; Shepherd, 1981).

In both experiments, the 85-year-old subjects had less education than the other three age groups. However, in 
Table 2

Mean Proportion Hits (H) and False Alarms (FA), and Mean $d^{\prime}$ Score Across Age, Cohort Relevance, and Face Familiarity

Cohort Relevance

\begin{tabular}{|c|c|c|c|c|c|c|c|c|c|c|c|c|}
\hline \multirow[b]{4}{*}{ Age Group } & \multirow{2}{*}{\multicolumn{6}{|c|}{ Young }} & \multirow{2}{*}{\multicolumn{6}{|c|}{ Old }} \\
\hline & & & & & & & & & & & & \\
\hline & \multicolumn{3}{|c|}{ Contemporary/Familiar } & \multicolumn{3}{|c|}{ Young/Unfamiliar } & \multicolumn{3}{|c|}{ Dated/Familiar } & \multicolumn{3}{|c|}{ Old/Unfamiliar } \\
\hline & $\mathrm{H}$ & $\mathrm{FA}$ & $d^{\prime}$ & $\mathrm{H}$ & $\mathrm{FA}$ & $d^{\prime}$ & $\mathrm{H}$ & FA & $d^{\prime}$ & $\mathrm{H}$ & FA & $d^{\prime}$ \\
\hline Young & .97 & .01 & 4.23 & .84 & .04 & 2.74 & .84 & .04 & 2.74 & .76 & .10 & 1.98 \\
\hline Younger old & .87 & .04 & 2.87 & .64 & .18 & 1.27 & .95 & .03 & 3.55 & .74 & .08 & 2.04 \\
\hline 76-year-olds & .80 & .10 & 2.10 & .64 & .20 & 1.21 & .90 & .05 & 2.91 & .65 & .20 & 1.23 \\
\hline 85 -year-olds & .58 & .20 & 1.04 & .57 & .24 & 0.87 & .77 & .11 & 1.97 & .58 & .26 & 0.83 \\
\hline
\end{tabular}

both experiments, the 85-year-old subjects showed a pattern of results identical to that for the 76-year-old subjects. Since the latter age group did not differ from the young and younger old subjects in educational background in either experiment, it seerns unlikely that the pattern of results obtained for the 85 -year-olds was due to level of schooling.

\section{GENERAL DISCUSSION}

In agreement with past research (Bartlett \& Leslie, 1986; Bartlett et al., 1989; Ferris et al., 1980; Smith \& Winograd, 1978), the results of the two experiments reported in this article indicate an age-related deficit in face recognition memory. Note, however, that the overall performance deficit was most pronounced in the two older age groups, and particularly in the oldest one. This result also replicates previous work (e.g., Bäckman et al., 1987; Bäckman \& Karlsson, 1986), suggesting a gradual decline in memory functioning from early to later stages of late adulthood. The present research was not concerned with determining the locus of the age-related deficit in face recognition memory. However, Bartlett et al. (1989) recently presented evidence suggesting that age-related differences in face recognition can be understood in terms of age-related deficits in (1) analytical matching of test items against representations in memory, and (2) distinctiveness of stimulus encoding.

The main purpose of the present research was to investigate whether there are age-related differences with respect to utilization of prior knowledge in remembering faces. The results concerning recognition of dated and contemporary famous faces pertaining to this issue were straightforward. The young adults performed better with contemporary than with dated famous faces in both experiments, whereas the opposite was true for all three older samples. Since normative data indicated greater knowledge of contemporary than of dated famous persons for young adults and vice versa for the groups of older adults, the obtained pattern of results thus indicates that the ability to utilize prior knowledge to enhance face recognition is present in all of the age groups examined.

Bäckman and Herlitz (1990) found that a group of adults between 60 and 70 years of age showed better recognition performance with dated than with contemporary famous faces. The results of the present study replicate and extend this finding, indicating that young adults as well as older adults in the middle 70 s and 80 s benefit from prior knowledge in the context of face recognition. Thus, there is accumulating evidence against the contention that prior knowledge influences episodic memory at retrieval rather than at encoding (Alba \& Hasher, 1983); if that would be the case, one should not expect effects of prior knowledge in recognition tasks involving a substantial amount of retrieval support. Rather, the present data are in agreement with the position taken by Bäckman and Herlitz (1990) that prior knowledge may affect memory at both encoding and retrieval.

Furthermore, the results of Experiment 1 showed that there was no differential benefit of a richer presentation format for the older adults. All age groups benefited equally much from increasing richness of the materials; recognition performance was better in the face plus name than in the face condition, which, in turn, yielded better performance than the name condition did. Past research on verbal (e.g., Bäckman \& Nilsson, 1984; Dick et al., 1989; Sharps \& Gollin, 1988) as well as nonverbal (e.g., Sharps \& Gollin, 1987; Waddell \& Rogoff, 1981, 1987) memory has indicated a disproportionate improvement in performance of older adults as a function of increasing richness of materials. Such an outcome is consistent with the view that older adults have a deficit in self-initiated recoding operations and therefore benefit selectively from a rich presentation format (e.g., Bäckman, 1985a; Craik, 1983). However, whereas memory was tested by means of free recall in the studies showing an age-related benefit of increasing item richness, a recognition test was used in the present research. Conceivably, this difference in retrieval conditions contributed to the mixed results. That is, the potential benefit of a rich input for the older age groups may have been masked by the richness of the retrieval information provided in all encoding conditions in Experiment 1. Previous work has shown that the effects of manipulations of both environmental context (Godden \& Baddeley, 1975, 1980; S. M. Smith, Glenberg, \& Bjork, 1978) and internal states (see Eich, 1980, for a review) disappear when extra retrieval information (e.g., copy cues) is provided. These data, as well as the present finding that the older adults were not selectively helped by a rich input, may be explained by assuming that several manipulations at encoding affect the accessibility of the memorial representation, but not the evaluation of 
whether the item was in fact previously presented (Baddeley, 1982).

It may also be noted that the results concerning presentation format did not indicate a deficit among older adults in utilizing cognitive support in terms of a rich input; rather, the data suggested age equivalence in utilization of this form of support. As discussed in the introductory section, although several studies have reported a selective improvement of older adults as a function of increasing cognitive support, the result of a similar improvement of young and older adults when task conditions become more supportive has also been reported in previous investigations (Bäckman et al., 1990).

Perhaps the most interesting finding of this research was that the young and younger old adults performed better with both familiar and unfamiliar cohort-relevant faces, whereas the 76- and 85-year-olds did so with familiar but not unfamiliar faces. Bartlett and Leslie (1986) reported higher recognition performance for young than for old unfamiliar faces among young subjects, whereas their older subjects showed no effect of age of face. Bartlett and Leslie pointed out that these data should be treated with caution, since the degree of match between subject age and face age was greater for the young than for the old. However, this argument cannot be applied to the present data, because the ages of the old unfamiliar faces varied between 69 and 85 years, with a mean of 76.2 years. Thus, if anything, the degree of match was greatest for the 76-year-olds. Nevertheless, this group of subjects and the group of 85-year-olds performed at the same level for both types of unfamiliar faces. The interesting question, then, is why this age-related difference in pattern of performance occurred for unfamiliar but not for familiar faces. That is, why is it that individuals in the middle 70 s and 80 s are equally likely as young and younger old adults to utilize prior knowledge in recognizing familiar faces, despite failing to do so in recognizing unfamiliar faces?

One explanation for this result is that there is a change of prior knowledge for unfamiliar faces throughout the life span, from greater knowledge of young faces, through greater knowledge of old faces, to equivalent knowledge of young and old faces. The possibility that young adults have more knowledge of young faces, whereas older adults have equivalent knowledge of young and old faces, was discussed by Bartlett and Leslie (1986). However, with respect to the results of Experiment 2 in the present study, this explanation has to be refuted. There is no compelling reason why there would be a shift from greater knowledge for old than for young faces among younger old adults to equivalent knowledge for both types of faces for 76-year-olds; in fact, on logical grounds, the opposite change would appear more likely. Thus, the position taken here is that the lack of effect of age of face among 76- and 85-year-olds is due to a failure in utilizing prior knowledge in recognizing unfamiliar old faces, rather than to changes in this type of prior knowledge in late life.
There is one obvious difference between recognizing familiar and unfamiliar faces. Familiar faces, as opposed to unfamiliar faces, may be known not from single presentations, but as a result of several exposures, such as pictures, films, and live exposures (Ellis, 1981; Ellis, Shepherd, \& Davies, 1979). Thus, the representation of familiar faces is richer, and it may involve various types of verbal features (e.g., semantic, contextual) in addition to physical features. As a consequence, familiar faces can usually be identified correctly despite changes in context. pose, or expression, although such changes are detrimental to recognition of unfamiliar faces (Ellis, 1981). This rich and multiple representation in the case of familiar faces accounts for the present finding that familiar faces were generally better recognized than unfamiliar faces (cf. Paivio, 1971; see also Bruce, 1979). Thus, the recognition advantage for cohort-relevant familiar faces observed for all age groups may be due to the fact that prior knowledge in the form of visual and verbal information aided the recognition process.

With respect to unfamiliar faces, the recognition process has to be based on physical and structural features of the faces to be remembered. Although older adults may have more appropriate schemata for the encoding of old rather than young unfamiliar faces, whereas the reverse may be true for young adults (Elliott et al., 1973; Shepherd, 1981), there is no semantic and contextual knowledge to aid the recognition of cohort-relevant unfamiliar faces. Accordingly, the results of the present research suggest that the ability to utilize prior knowledge in face recognition is preserved in very old age, provided that the underlying knowledge representation is rich. When recognition is not aided by a rich representation-that is, when only prototypical representations of physical features of faces are available - there appears to be an age-related deficit in utilization of prior knowledge that occurs after 70 years of age.

It is of interest to compare this pattern of results with the data reported recently by Bäckman and Herlitz (1990). They found that although both normal old adults and mildly demented patients with Alzheimer's disease were more knowledgable about dated than about contemporary famous persons, the normal old, as opposed to the demented, performed better with dated than with contemporary faces in an episodic recognition test. These data suggest that Alzheimer's disease is associated with a deficit in the ability to utilize prior knowledge in recognition of familiar faces. Comparing these data with those of the present study, an intriguing pattern emerges. For young and younger old adults, previous knowledge appears to aid recognition of both unfamiliar and familiar faces. In other words, a rich representation of the face to be recognized is not a necessary prerequisite for improving recognition in these groups of subjects. In contrast, for old and very old adults, successful utilization of prior knowledge in recognizing faces seems to be dependent on a rich representation, whereas for Alzheimer's 
patients, there is no benefit of previous knowledge despite greater visual and semantic knowledge of dated than of contemporary famous faces.

This pattern of results is in agreement with current conceptualizations of memory aging, which state that, with increasing adult age, there is an increase in the degree of contextual and cognitive support that is required for one to optimize episodic remembering (see, e.g., Bäckman, 1985a, 1989; Craik, 1983; Craik et al., 1987). In addition, the data are congruent with the notion that a distinguishing feature between normal aging and dementia is that, although normal old individuals may require more or less support, depending, for example, on age or level of education, they are typically able to utilize support for remembering, whereas demented patients are not (Bäckman et al., 1990).

\section{REFERENCES}

Alba, J. W., \& HASher, L. (1983). Is memory schematic? Psychological Bulletin, 93, 203-231.

Arbuckle, T. Y., Gold, D., \& ANDres, D. (1986). Cognitive functioning of older people in relation to social and personality variables. Psychology \& Aging, 1, 55-62.

ARENBERG, D. (1968). Input modality in short-term retention in old and young adults. Joumal of Gerontology, 23, 462-465.

BadDeley, A. D. (1982). Domains of recollection. Psychological Review, 89, 708-729.

BÄCKMAN, L. (1985a). Compensation and recoding: A framework for aging and memory research. Scandinavian Journal of Psychology, 26, 193-207.

BÄCKMAN, L. (1985b). Further evidence for the lack of adult age differences on free recall of subject-performed tasks: The importance of motor action. Human Leaming, 4, 79-87.

BäcKman, L. (1986). Adult age differences in cross-modal recoding and mental tempo, and older adults' utilization of compensatory task conditions. Experimental Aging Research, 12, 135-140.

BäcKMAN, L. (1989). Varieties of memory compensation by older adults in episodic remembering. In L. W. Poon, D. C. Rubin, \& B. A. WilSon (Eds.), Everyday cognition in adulthood and late life (pp. 509. 544). New York: Cambridge University Press.

BÄCKMAN, L., \& HerLITZ, A. (1990). The relationship between prior knowledge and face recognition memory in normal aging and $\mathrm{Alz}$ heimer's disease. Journal of Gerontology: Psychological Sciences, 45, 94-100.

Bä́ckman, L., Herlitz, A., \& Karlsson, T. (1987). Pre-experimental knowledge facilitates episodic recall in young, young-old, and oldold adults. Experimental Aging Research, 13, 89-91.

Bäckman, L., KarLsSON, T. (1985). The relation between level of general knowledge and feeling-of-knowing: An adult age study. Scandinavian Journal of Psychology, 26, 249-258.

BÄCKMAN, L., \& KARLSSON, T. (1986). Episodic remembering in young adults, 73-year-olds, and 82-year-olds. Scandinavian Joumal of Psychology, 27, 320-325.

Bäckman, L., Mäntylä, T., Herutz, A. (1990). The optimization of episodic remembering in old age. In P. B. Baltes \& M. M. Baltes (Eds.), Successful aging: Perspectives from the behavioral sciences (pp. 118-163). New York: Cambridge University Press.

Bä́ckman, L., \& NiLsson, L.-G. (1984). Aging effects in free recall: An exception to the rule. Human Learning, 3, 53-69.

Bäckman, L., \& NiLsson, L.-G. (1985). Prerequisites for lack of age differences in memory performance. Experimental Aging Research, 11, 67-73.

BARRETT, T. R., \& WRIGHT, M. (1981). Age-related facilitation in recall following semantic processing. Journal of Gerontology, 36, 194-199.
Bartlett, J. C., \& Leslie, J. E. (1986). Aging and memory for faces versus single views of faces. Memory \& Cognition, 14, 371-381.

Bartlett, J. C., Lesle, J. E., Tubas, A., Fulton, A. (1989). Aging and memory for pictures of faces. Psychology \& Aging, 4, 276-283

Brigham, J. C., BArKowitz, P. (1978). Do "They all look alike?" The effects of race, sex, experience, and attitudes on the ability to recognize faces. Journal of Applied Social Psychology, 8, 306-318.

Brigham, J. C., Williamson, N. L. (1979). Cross-racial recognition and age: When you're over 60 , do they still "all look alike?" Personality \& Social Psychology Bulletin, 5, 218-222.

BRUCE, V. (1979). Searching for politicians: An information-processing approach to face recognition. Quarterly Joumal of Experimental Psychology, 31, 373-395.

Chance, J., Goldstein, A. G., \& McBride, L. (1975). Differential experience and recognition memory for faces. Journal of Social Psychology, 97, 243-253.

Crajk, F. I. M. (1983). On the transfer of information from temporary to permanent memory. Philosophical Transactions of the Royal Society of London, 302, 341-359.

Craik, F. I. M. (1985). Paradigms in human memory research. In L.-G. Nilsson \& T. Archer (Eds.), Perspectives on learning and memory (pp. 247-277). Hillsdale, NJ: Erlbaum.

Craik, F. I. M., Byrd, M., Swanson, J. M. (1987). Patterns of memory loss in three elderly samples. Psychology \& Aging, 2, 79-86.

Craik, F. I. M., Rabinowitz, J. C. (1984). Age differences in the acquisition and use of verbal information. In $\mathrm{H}$. Bouma \& $\mathrm{D}$. G. Bouwhuis (Eds.), Attention and performance (Vol. 10, pp, 471-500). London: Erlbaum.

Craik, F. I. M., \& Simon, E. (1980). Age differences in memory: The roles of attention and depth of processing. In L. W. Poon, J. L. Fozard, L. S. Cermak, D. Arenberg, \& L. W. Thompson (Eds.), New directions in memory and aging (pp. 95-112). Hillsdale, NJ: Erlbaum.

Dick, M. B., KeAN, M.-L., \& SANDS, D. (1989). Memory for action events in Alzheimer-type dementia: Further evidence for an encoding failure. Brain \& Cognition, 9, 71-87.

Dixon, R. A., BÄCkman, L. (in press). Reading and memory for prose in adulthood. In S. R. Yussen \& M. C. Smith (Eds.), Reading across the life span. New York: Springer.

Dixon, R. A., Hultsch, D. F., Simon, E. W., \& von Eye, A. (1984). Verbal ability and text structure effects on adult age differences in text recall. Joumal of Verbal Learning \& Verbal Behavior, 23, 569-578.

Eich, J. E. (1980). The cue-dependent nature of state-dependent retrieval. Memory \& Cognition, 8, 157-173.

Elliot,, E. S., Wills, E. J., \& GoldSTEIN, A. G. (1973). The effects of discrimination training on the recognition of white and oriental faces. Bulletin of the Psychonomic Society, 2, 71-73.

ELLIS, H. D. (1981). Theoretical aspects of face recognition. In G. M. Davies, H. D. Ellis, \& J. W. Shepherd (Eds.), Perceiving and remembering faces (pp. 171-197). London: Academic Press.

Ellis, H. D., Shepherd, J. W., Davies, G. M. (1979). Identification of familiar and unfamiliar faces from internal and extemal feanures: Some implications for theories of face recognition. Perception, 8, 431-439.

Erber, J. T., Galt, D., Botwinick, J. (1985). Age differences in the effects of contextual framework and word-familiarity on episodic memory. Experimental Aging Research, 11, 101-103.

Feinman, S., Entwistle, D. R. (1976). Children's ability to recognize other children's faces. Child Development, 47, 506-510.

Ferris, S. H., Crook, T., Clark, E., McCarthy, M., \& Rae, D. (1980). Facial recognition memory deficits in normal aging and senile dementia. Journal of Gerontology, 35, 707-714.

GALPER, R. E. (1973). "Functional race membership" and recognition of faces. Perceptual \& Motor Skills, 37, 455-462.

GODDEN, D. R. BADDELEY, A. D. (1975). Context-dependent memory in two natural environments: On land and under water. British Journal of Psychology, 66, 325-331.

Godden, D. R., BADDEley, A. D. (1980). When does context in- 
fluence recognition memory? British Journal of Psychology, 71, 99-104.

Hanley-DunN, P., \& McIntosh, J. L. (1984). Meaningfulness and recall of names by young and old adults. Joumal of Gerontology. 39. 583-585.

HuLtsCH, D. F. (1969). Adult age differences in the organization of free recall. Developmental Psychology, 1, 673-678.

HuLtsch, D. F. (1971). Adult age differences in free classification and free recall. Developmental Psychology, 4, 338-342.

Hultsch, D. F., Dixon, R. A. (1983). The role of pre-experimental knowledge in text processing in adulthood. Experimental Aging Research, 9, 17-22.

Hultsch, D. F., Dixon, R. A. (1984). Text processing in adulthood. In P. B. Baltes \& O. G. Brim, Jr. (Eds.), Life span development and behavior (Vol. 6, pp. 77-108). New York: Academic Press.

Hultsch, D. F., Dixon, R. A. (1990). Learning and memory in aging. In J. E. Birren \& K. W. Schaie (Eds.), Handbook of the psychology of aging (3rd ed., pp. 258-274). San Diego: Academic Press.

Hultsch, D. F., Pentz, C. A. (1980). Encoding, storage, and retrieval in adult memory: The role of model assumptions. In $\mathrm{L}$. W Poon, J. L. Fozard, L. S. Cermak, D. Arenberg, \& L. W. Thompson (Eds.), New directions in memory and aging (pp. 73-94). Hillsdale, NJ: Erlbaum.

Karlsson, T., Bäckman, L., Herlitz, A., Nilsson, L.-G., Winglad, B., Österlind, P.-O. (1989). Memory improvement at different stages of Alzheimer's disease. Neuropsychologia, 27, 737-742.

Kliegl, R. K., Smith, J., Baltes, P. B. (1989). Testing-the-limits and the study of adult age differences in cognitive plasticity of a mnemonic skill. Developmental Psychology, 25, 247-256

Malpass, R. S., \& Kavitz, J. (1969). Recognition of faces of own and other races. Joumal of Personality \& Social Psychology, 13 , 330-334.

McGhie, A., Chapman, J., \& Lawson, J. S. (1965). Changes in immediate memory with age. British Journal of Psychology, 59, 119-125.

Mitchell, D. B., Hunt, R., \& Schmitt, F. A. (1986). The generation effect and reality monitoring: Evidence from dementia and normal aging. Journal of Gerontology, 41, 79-94.

Nilsson, L.-G., Bäckman, L., Herlitz, A., Karlsson, T., ÖterLND, P. O., WINBLAD, B. (1987). Patterns of memory performance in young-old and old-old adults: A selective review. Comprehensive Gerontology, 1, 49-53.

Palvio, A. (1971). Imagery and verbal processes. New York: Hoit, Rinehart \& Winston.

Perlmutter, M., Metzger, R., Miller, K., \& Nezworski, T. (1980). Memory of historical events. Experimental Aging Research, 6, 47-60.
Rabinowitz, J. C., Crajk, F. I. M. (1986). Prior retrieval effects in young and old adults. Joumal of Gerontology, 41. 368-375.

Sharps, M. J. . Gollin, E. S. (1987). Memory for object locations in young and elderly adults. Joumal of Geronsology: Psychological Sciences, 42, 336-341.

Sharps, M. J., \& Gollin, E. S. (1988). Aging and free recall of objects located in space. Joumal of Gerontology: Psychological Sciences, 43, 8-11.

Shepherd, J. W. (1981). Social factors in face recognition. In G. M. Davies, H. D. Ellis, \& J. W. Shepherd (Eds.), Perceiving and remembering faces (pp. 55-79). London: Academic Press.

Shepherd, J. W., Deregowski, J. B . Ellus, H. D. (1974). A crosscultural study of recognition memory for faces. International Journal of Psychology. 9, 205-211.

Simon, E. (1979). Depth and elaboration of processing in relation to age. Joumal of Experimental Psychology: Human Learming \& Memory. 5, $115-124$.

SMith, A. D. \& WinogRAd, E. (1978). Adult age differences in remembering faces. Developmental Psychology, 14, 443-444.

Smith, S. M., GlenberG, A. [M.], \& Bjork. R. A. (1978). Environmental context and human memory. Memory \& Cognition, 6, 342-353.

TAUB, H. A. (1972). A comparison of young adult and old groups on various digit span tasks. Developmental Psychology, 6, 60-65.

WADDELL, K. J., RoGoFF, B. (1981). Effect of contextual organization on spatial memory of middle-aged and older women. Developmental Psychology, 17, 878-885.

WADDELL, K. J., \& RociOFF, B. (1987). Contextual organization and intentionality in adults' spatial memory. Developmental Psychology. 23, 514-520

WINOGRAD, E. \& SimON, E. W. (1980). Visual memory and imagery in the aged. In L. W. Poon, J. L. Fozard, L. S. Cermak, D. Arenberg, \& L. W. Thompson (Eds.), New directions in memory and aging (pp. 485-506). Hillsdale, NJ: Erlbaum.

Worden, P. E., Sherman-Brown, S. S. (1983). A word-frequency cohort effect in young versus elderly adults' memory for words. Developmental Psychology, 19,521-530

YeSAVAGE, J. A. (1985). Nonpharmacologic treatments for memory losses with normal aging. American Journal of Psychiatry, 142, $600-605$

(Manuscript received November 20, 1989; revision accepted for publication July 15, 1990.) 